\title{
Early diagnosis and stage classification of vocal cord abductor paralysis in patients with multiple system atrophy
}

Eiji Isozaki, Akira Naito, Satoshi Horiguchi, Rie Kawamura, Tetsuro Hayashida, Hitoshi Tanabe
Conclusions-Laryngoscopy during sleep can disclose subclinical VCAP, making an early diagnosis of VCAP in patients with multiple system atrophy. Stage 2 of VCAP seems to be a suitable stage for tracheostomy in patients with multiple system atrophy.

\section{$(尹$ Neurol Neurosurg Psychiatry 1996;60:399-402)}

Keywords: multiple system atrophy; vocal cord abductor paralysis; sleep; stridor

Patients with multiple system atrophy presenting with vocal cord abductor paralysis (VCAP) can suddenly die during the night due to choking. ${ }^{1-3}$ Many previous investigators have emphasised that VCAP often requires emergency tracheostomy..$^{2-8}$ However, we consider that sudden death may occur due to delay in the diagnosis of VCAP or hesitation in performing tracheostomy as many patients with multiple system atrophy and VCAP do not develop either speech disturbances ${ }^{5}$ or severe swallowing disturbance. ${ }^{7}$ There are two serious problems in the management of multiple system atrophy. How is it possible to make an early and correct diagnosis of VCAP? When should tracheostomy be performed after the diagnosis of VCAP? To clarify these situations, we analysed vocal cord movement by laryngoscopy during wakefulness and also during sleep induced by diazepam. We have also made the first attempt to classify VCAP by the stage of severity and discuss the timing of tracheostomy.

\section{Materials and methods}

Seven patients with multiple system atrophy with nocturnal stridor and five control patients were studied (table 1). Three patients with multiple system atrophy (2, 3, and 5) had already been analysed by laryngeal EMG. ${ }^{9}$ \begin{abstract}
during both wakefulness and sleep, stage 1 (mild VCAP) with normal movement during wakefulness and paradoxical movement during sleep, stage 2 (moderately severe VCAP) with abduction restriction during wakefulness and paradoxical movement during sleep, and stage 3 (severe VCAP) with an almost midline position for the vocal cords during both wakefulness and sleep.
\end{abstract}

Department of

Neurotology, Tokyo

Metropolitan

Neurological Hospital,

Tokyo, Japan

A Naito

$S$ Horiguchi

R Kawamura

T Hayashida

Correspondence to:

Dr Eiji Isozaki, Department of Neurology, Tokyo Metropolitan Neurological Hospital, 2-6-1, Musashidai, Fuchu, Tokyo 183, Japan.

Received 9 June 1995 and in final revised form 8 December 1995

Accepted 20 December 1995

Table 1 Neurological features of patients with multiple system atrophy with vocal cord abductor paralysis

\begin{tabular}{lllllllll}
\hline & \multirow{7}{*}{$\begin{array}{l}\text { Duration } \\
\text { Patients }\end{array}$} & \multicolumn{2}{l}{ Neurological signs } \\
\cline { 3 - 9 } & Age/sex & $(y)$ & $C$ & $E$ & $P$ & $B D$ & $O H$ & Dysphagia \\
\hline 1 & $49 / \mathrm{F}$ & 7 & + & + & + & + & + & Mild \\
2 & $63 / \mathrm{M}$ & 8 & + & + & + & + & + & Mild \\
3 & $70 / \mathrm{F}$ & 2 & + & + & + & + & + & Mild \\
4 & $62 / \mathrm{M}$ & 4 & + & + & + & + & + & Mild \\
5 & $61 \mathrm{M}$ & 6 & + & + & + & + & + & Tube feeding \\
6 & $68 / \mathrm{F}$ & 2 & + & + & + & + & + & Tube feeding \\
7 & $64 / \mathrm{M}$ & 6 & + & + & + & + & + & +
\end{tabular}

$\mathrm{C}=$ Cerebellar signs; $\mathrm{E}=$ extrapayramidal signs; $\mathrm{P}=$ pyramidal signs; $\mathrm{BD}=$ bladder disturbance; $\mathrm{OH}=$ orthostatic hypotension. 
Table 2 Laryngological findings of patients with multiple system atrophy and vocal cord abductor paralysis (VCAP)

\begin{tabular}{|c|c|c|c|c|c|c|c|c|c|}
\hline \multirow[b]{2}{*}{ Patients } & \multirow{2}{*}{$\begin{array}{l}\text { Onset of } \\
\text { VCAP }\end{array}$} & \multirow[b]{2}{*}{ Disability } & \multicolumn{2}{|l|}{ Stridor } & \multicolumn{3}{|c|}{$A B G A(m m H g)$} & \multirow{2}{*}{$\begin{array}{l}\text { VCAP- } \\
\text { period }\end{array}$} & \multirow[b]{2}{*}{ Laryngoscopy } \\
\hline & & & Awake & Sleep & $p H$ & $\mathrm{PCO}_{2}$ & $\mathrm{PO}_{2}$ & & \\
\hline $\begin{array}{l}1 \\
2 \\
3 \\
4 \\
5 \\
6 \\
7\end{array}$ & $\begin{array}{l}7 \\
8 \\
3 \\
4 \\
5 \\
2 \\
6\end{array}$ & $\begin{array}{l}\text { Moderate } \\
\text { Moderate } \\
\text { Mild } \\
\text { Moderate } \\
\text { Moderate } \\
\text { Mild } \\
\text { Moderate }\end{array}$ & $\begin{array}{l}- \\
- \\
- \\
- \\
\overline{+} \\
+\end{array}$ & $\begin{array}{l}+ \\
++ \\
+ \\
++ \\
++ \\
+ \\
++\end{array}$ & $\begin{array}{l}7 \cdot 40 \\
7 \cdot 33 \\
7 \cdot 34 \\
7 \cdot 37 \\
7 \cdot 38 \\
7 \cdot 44 \\
7 \cdot 34\end{array}$ & $\begin{array}{l}42 \\
42 \\
44 \\
45 \\
47 \\
47 \\
55\end{array}$ & $\begin{array}{l}83 \\
74 \\
72 \\
58 \\
76 \\
64 \\
68\end{array}$ & $\begin{array}{l}9 \text { months } \\
5 \text { months } \\
>1 \mathrm{y} \\
12 \text { days } \\
>1.5 \mathrm{y} \\
10 \text { months } \\
2 \text { days }\end{array}$ & $\begin{array}{l}\text { Stage 1 } \\
\text { Stage 1 } \\
\text { Stage 2 } \\
\text { Stage 2 } \\
\text { Stage 2 } \\
\text { Stage 1 } \\
\text { Stage 3 }\end{array}$ \\
\hline
\end{tabular}

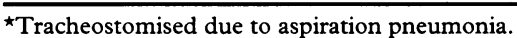

ABGA = Arterial blood gas analysis during wakefulness; VCAP-period = period from diagnosis of VCAP to tracheostomy, if performed.

The controls included three patients with nonneurological disorders as normal controls and two with amyotrophic lateral sclerosis with bulbar symptoms as disease controls. Table 2 shows the disability score and the VCAP related findings, including arterial blood gas analysis, during wakefulness around the time of laryngoscopy. Disability of the patients was,

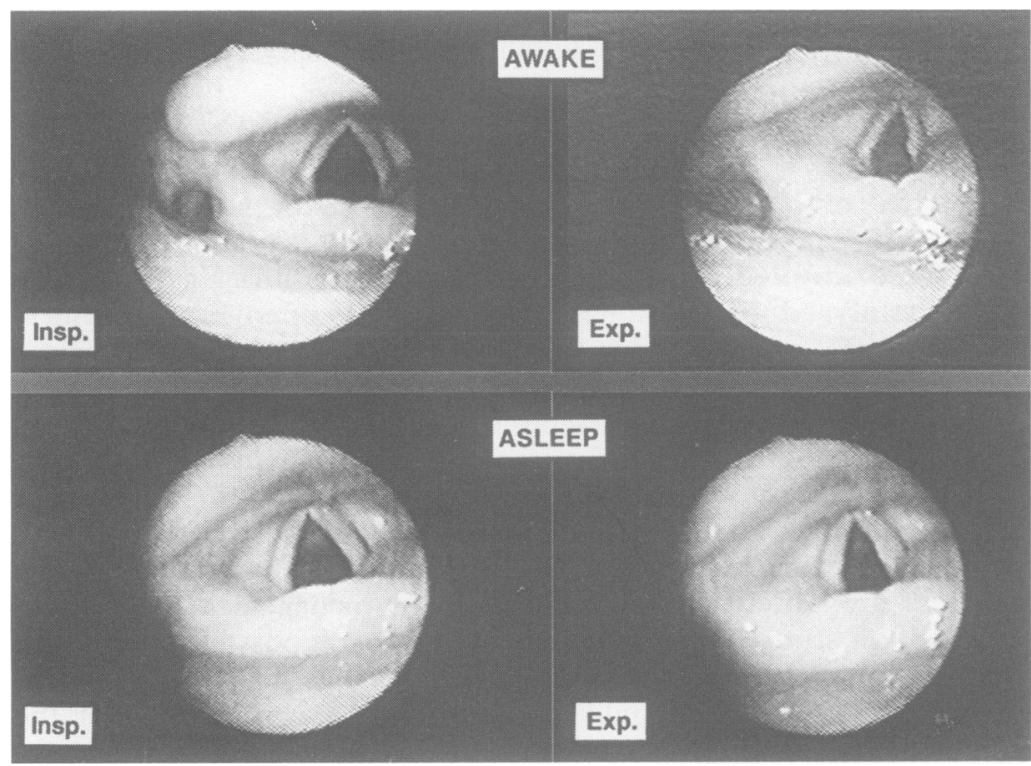

Figure 1 Vocal cord movement in a normal subject. The vocal cords abduct on inspiration and slightly adduct on expiration. There are no significant changes between wakefulness and sleep.

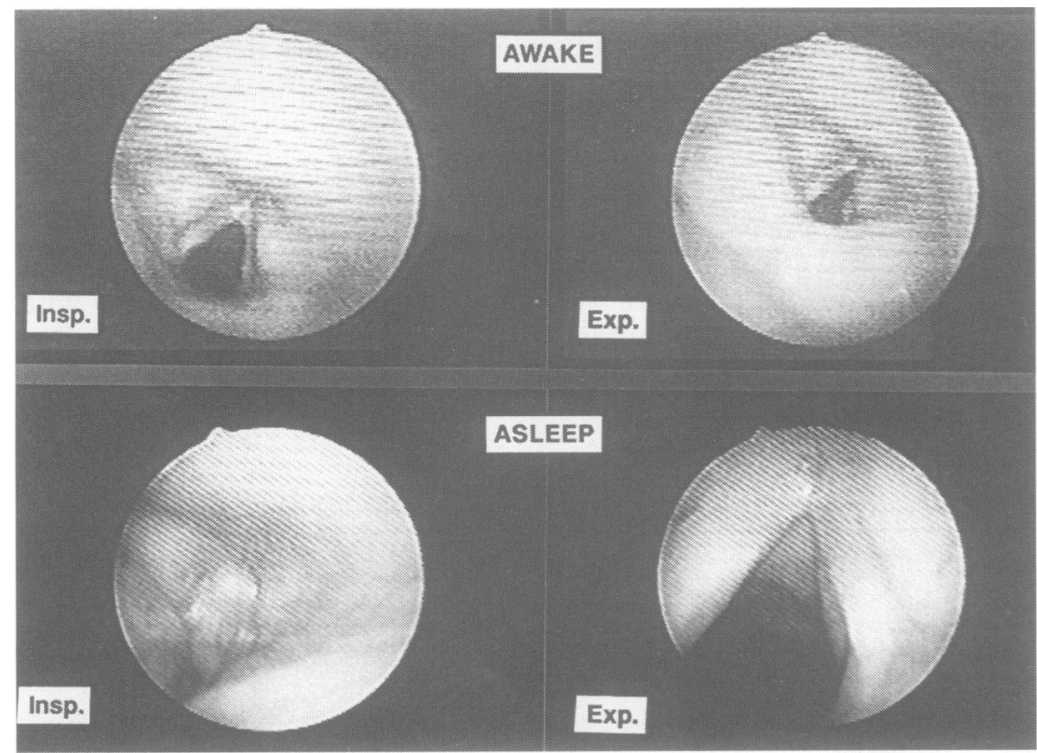

Figure 2 Mild vocal cord abductor paralysis (stage 1) in multiple system atrophy (patient 6). Vocal cord movement is normal while awake, but paradoxical during sleep: the vocal cords adduct on inspiration rather than on expiration. for convenience, evaluated as follows: "mild" means ambulatory with or without a cane, "moderate" means ambulatory with a walker or wheelchair, and "severe" means bedridden. Vocal cord movement was analysed by laryngoscopy while the patients were awake and during sleep induced by intravenous treatment with 5 to $10 \mathrm{mg}$ diazepam. Pictures were monitored on a video display unit and recorded on a videocassette. An intratracheal tube was always available in case of emergency.

\section{Results}

Figure 1 shows the vocal cord movement in a normal subject, with no significant difference between wakefulness and sleep: the vocal cords abduct fully on inspiration and adduct slightly on expiration. A similar pattern was seen in the other four controls. In the patients with multiple system atrophy, three different patterns were found. In patient 6 (fig 2), although the vocal cords functioned normally during wakefulness, they adducted on inspiration and abducted on expiration during sleep. Such a nocturnal paradoxical movement was also seen in patients 1 and 2. Arterial blood gas analysis while awake in this group showed mild to moderate hypoxaemia (table 2 ). In patient 3 (fig 3), laryngoscopy showed mild abduction restriction of the vocal cords while awake and paramedian fixation with paradoxical movement during sleep. A similar pattern occurred in patients 4 and 5 . The pattern was more severe in patient 4 . The arterial blood gas analysis during wakefulness in this group showed moderately severe hypoxaemia with or without hypercapnia. In patient 7 (fig 4), the vocal cords took almost a paramedian to midline position, resulting in a slit-like glottis aperture. Moreover, the small aperture became narrower during sleep, showing an almost midline position of the vocal cords in association with high pitched and heavy inspiratory stridor. In this patient, intratracheal intubation was carried out immediately after the finding because of the danger of choking to death. The arterial blood gas analysis

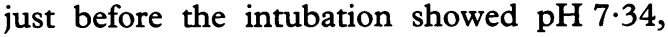
$\mathrm{PCO}_{2} 55 \mathrm{~mm} \mathrm{Hg}, \mathrm{PO}_{2} 68 \mathrm{~mm} \mathrm{Hg}$. Table 1 and 2 indicate that there were no relations between VCAP and duration of illness, disability score or other neurological findings apart from bladder disturbance. High pitched inspiratory stridor was audible during sleep in all the patients and while awake in patient 7 . 


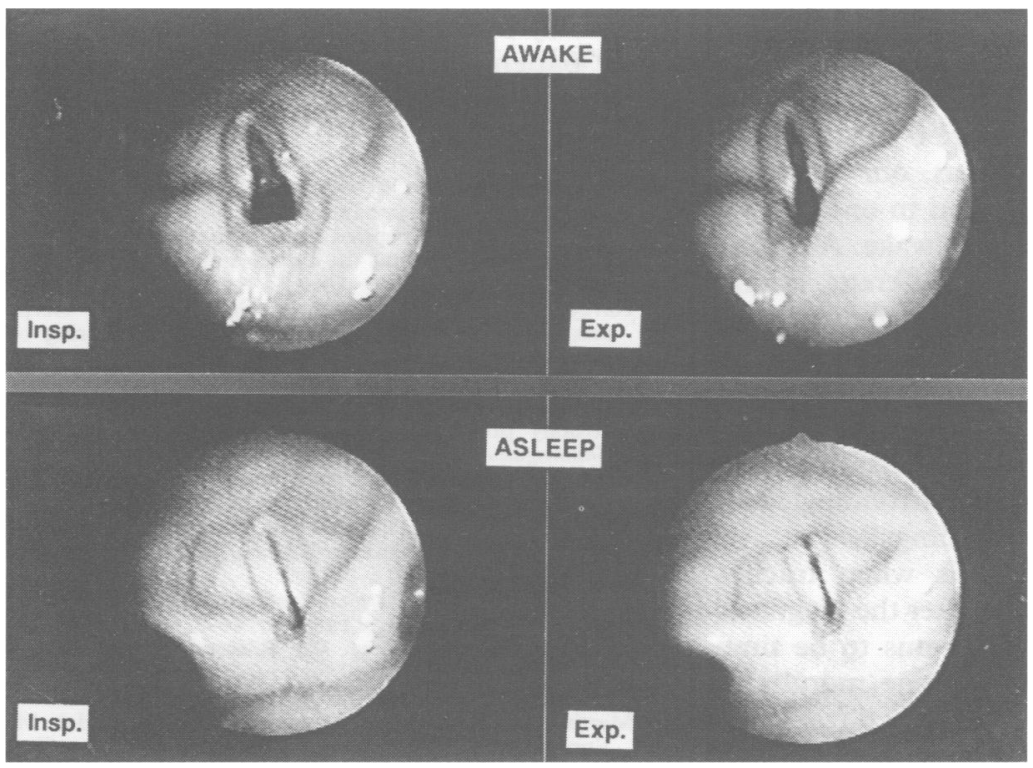

Figure 3 Moderately severe vocal cord abductor paralysis (stage 2) in multiple system atrophy (patient 3). Vocal cords show mild abduction restriction during wakefulness and paramedian fixation with paradoxical movement during sleep.

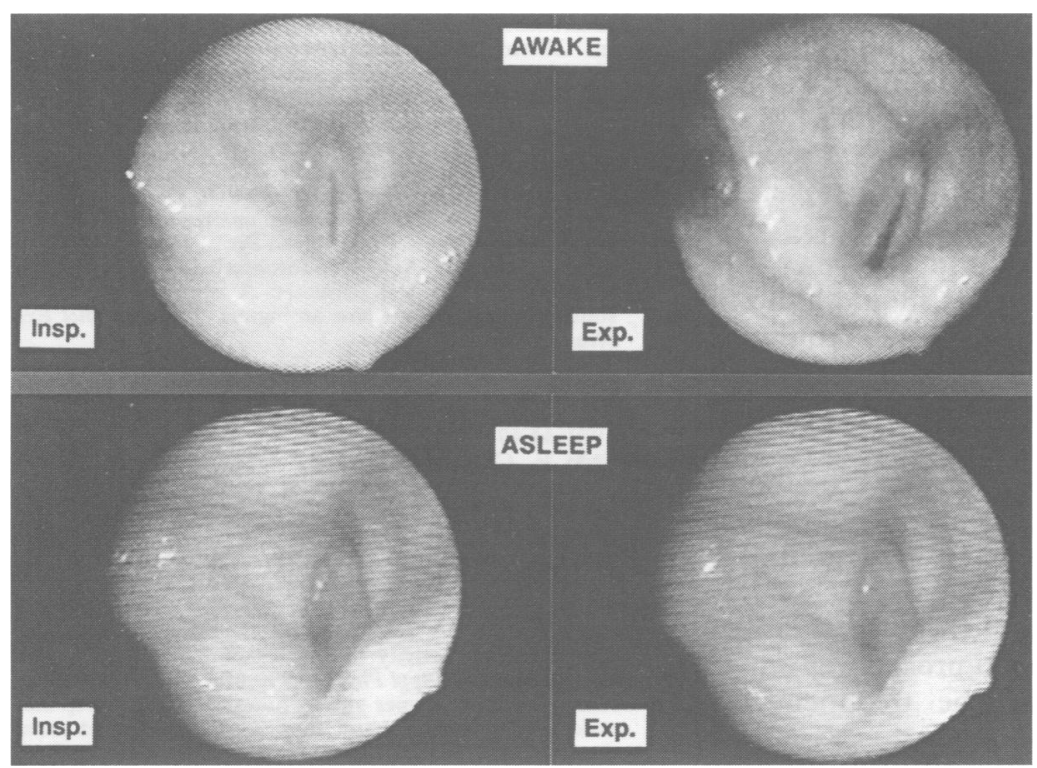

Figure 4 Pronounced vocal cord abductor paralysis (stage 3) in multiple system atrophy (patient 7). Vocal cords take an almost midline position while awake and asleep. Intratracheal intubation was done immediately after this finding.

\section{Discussion}

ADVANTAGES OF LARYNGOSCOPY DURING SLEEP The present study showed three advantages of laryngoscopy during sleep (sleeplaryngoscopy). Firstly, it permits an early diagnosis of VCAP because the vocal cords in patients with multiple system atrophy and VCAP showed dramatic paradoxical movement only during sleep, although their movement when awake was normal. Considering that the routine laryngoscopic examination is usually performed during wakefulness in daytime, sleep-laryngoscopy is definitely required for those patients with multiple system atrophy who snore heavily, to disclose subclinical VCAP.

Secondly, it is sometimes difficult to differentiate true abduction restriction of the vocal cords due to VCAP from seeming abduction restriction due to some aspiration in patients with multiple system atrophy. The vocal cords in the patients with dysphagia have a tendency to reflective adduction based on a laryngeal protective mechanism against aspiration. ${ }^{10}$ Hypotonus of the laryngeal muscles during sleep seems to reduce such an excessive reflective adduction.

Thirdly, sleep-laryngoscopy is able to define the sound source for snoring or stridor. ${ }^{11}$ The difference is clinically important as non-life threatening ordinary snoring, which appears in healthy normal subjects, is usually derived from the pharyx in the area between the epiglottis and the choanae, ${ }^{12}$ whereas life threatening inspiratory stridor in patients with multiple system atrophy is from the vocal cords of the larynx. Therefore, sleeplaryngoscopy is useful to identify dangerous "snoring"-namely, stridor.

We speculate that VCAP becomes dramatically apparent during sleep because laryngeal muscle tone in patients with multiple system atrophy with VCAP is prominently adduction as the sole abductor-the posterior cricoarytenoid muscle-is selectively involved in neurogenic atrophy. ${ }^{13-15}$ Also, all the laryngeal muscles lose their activities when asleep. ${ }^{16-18}$ As a result, the adduction predominant larynx can be easily pulled inwards and downwards and then collapsed by intratracheal negative pressure on inspiration. Such an aerodynamic inbalance between the laryngeal muscle tone and airflow pressure seems to cause sleep induced paradoxical movement of the vocal cords. Moreover, our laryngeal EMG studies of patients 2,3 , and 5 performed previously showed that the inspiratory activity of the adductor (the thyroarytenoid muscle) and the fade out phenomenon of the abductor might also participate in the mechanism of sleep induced exacerbation. ${ }^{9}$ We have divided VCAP into two types, the paralytic type in multiple system atrophy and the non-paralytic type in Parkinson's disease. ${ }^{19}$ The second was thought to be caused by the persistent overactivity of the intrinsic laryngeal muscles, possibly derived from supranuclear involvement. Because some patients with multiple system atrophy develop predominant extrapyramidal signs, VCAP in such patients might be caused by a supranuclear mechanism (the nonparalytic type of VCAP) in addition to the paralytic type.

\section{STAGE CLASSIFICATION OF VCAP}

We divided VCAP into four stages (table 3) according to the laryngoscopic findings. Then, referring to the clinical findings and to our previous chronological study, ${ }^{20}$ we hypothe-

Table 3 Stage classification of vocal cord abductor paralysis on laryngoscopy

\begin{tabular}{|c|c|c|}
\hline \multirow[b]{2}{*}{ Stage } & \multicolumn{2}{|l|}{ Vocal cord movement } \\
\hline & Awake & Asleep \\
\hline $\begin{array}{l}\text { Stage } 0 \text { (normal) } \\
\text { Stage } 1 \text { (mild) } \\
\text { Stage } 2 \text { (moderate) } \\
\text { Stage } 3 \text { (severe) }\end{array}$ & $\begin{array}{l}\text { Normal } \\
\text { Normal } \\
\text { Abduction restriction } \\
\text { Midline }\end{array}$ & $\begin{array}{l}\text { Unchanged } \\
\text { Paradoxical } \\
\text { Paradoxical } \\
\text { Midline }\end{array}$ \\
\hline
\end{tabular}


sised that VCAP might deteriorate from stage 1 to stage 3 through stage 2 . However, there may be some exceptions in this order, such as a "skip" deterioration from stage 0 to stage 2 or from stage 1 to stage 3 , as our previous chronological study was limited to one patient who was examined only while awake. Also, the stage of sleep depth may be different among the individual patients under drug induced sleep and it is possible that the severity of VCAP may depend on this the depth of sleep, as Kakitsuba et al $^{11}$ have already pointed out. To confirm the stage classification more patients need to be studied chronologically, with concomitant EMG recordings.

The perplexing problem is when tracheostomy should be performed after the diagnosis of VCAP. In stage 1, there seems to be time enough before tracheostomy; nine months in patient 1 and 10 months in patient 6 (table 2). Tracheostomy in stage 3 is obviously too late. Therefore, stage 2 seems to be the suitable stage for tracheostomy. Table 2 indicates two clinical findings that are helpful in identifying this stage - namely, when the inspiratory stridor becomes audible, not only during sleep but also during wakefulness and when the arterial bicarbonate concentration rises while awake. However, the present study showed that arterial blood gas analysis during wakefulness is not always useful for evaluating the severity of VCAP, as most critical respiratory failure appears during sleep. It should also be borne in mind that severe VCAP requiring tracheostomy can develop even in the early stage of the disease when patients are still capable of walking, eating, and drinking.

In the past, tracheostomy was the only treatment for VCAP in patients with multiple system atrophy. Some tracheostomised patients could speak by setting a speech valve in a cuffless tracheal cannula. ${ }^{20}$ At present, however, there are four main procedures other than a tracheostomy for the treatment of laryngeal airway stenosis due to VCAPnamely, arytenoidectomy, cordectomy, cord lateralisation, and laryngeal re-innervation. ${ }^{21} 22$ For patients with multiple system atrophy, however, there has so far been only one report on the management of vocal cord lateralisation without the need for a permanent tracheostomy. ${ }^{23}$ The reason why these airway relieving procedures have not been applied to patients with multiple system atrophy might be related to the fact that multiple system atrophy is a progressive neurodegenerative disorder associated with severe aspiration sooner or later. Nevertheless, we think that procedures for airway restoration should be attempted in more patients with multiple system atrophy presenting with VCAP.

1 Bannister R, Gibson W, Michaels L, Oppenheimer DR. Laryngeal abductor paralysis in multiple system atrophy. A report on three necropsied cases, with observation on the laryngeal muscles and the nuclei ambigui. Brain 1981; 104:351-68. 2 Kavey NB, Whyte J, Blitzer A, Gidro-Frank S. Sleepsleep apnea. Laryngoscope 1989;99:851-4.

3 Isozaki E, Miyamoto K, Osanai R, Hayashida T, Tanabe H. Clinical studies of 23 patients with multiple system atrophy presenting with vocal cord paralysis. Rinsho Shinkeigaku 1991;31:249-24.

4 Israel RH, Marino JM. Upper airway obstruction in the Shy-Drager syndrome. Ann Neurol 1977;2:83.

5 Williams A, Hanson D, Calne DB. Vocal cord paralysis in the Shy-Drager syndrome. $\mathcal{F}$ Neurol Neurosurg Psychiatry 1979;42:151-3.

6 Longridge NS. Bilateral vocal cord paralysis in Shy-Drager syndrome. F Otolaryngol 1987;16:146-8.

7 Palesse N, Marelli A, Legge MP. Bilateral abductor paralysis of the vocal cords in the course of neurological diseases: report of 5 cases. Ital $₹$ Neurol Sci 1988;9:59-62.

8 Martinovits G, Leventon G, Goldhammer Y, Sadeh M. Vocal cord paralysis as a presenting sign in the ShyDrager syndrome. $f$ Laryngol Otol 1988;102:280-1.

9 Isozaki E, Osanai R, Horiguchi S, Hayashida T, Hirose K, Tanabe H. Laryngeal electromyography with separated surface electrodes in patients with multiple system atrophy presenting with vocal cord paralysis. F Neurol 1994;

10 Widdicombe JG. Reflexes from the upper respiratory tract. In: Chernick NS, Widdicombe JG, eds. Handbook of physiology. Section 3, The respiratory system, Bethesda: American Physiological Society, 1986:363-94.

11 Kakitsuba N, Sadaoka T, Motoyama S, Takahashi $H$. Snoring due to inspiratory vibration of the vocal folds. fibi Rinsho 1988;81:423-31.

12 Fairbanks DNF. Snoring. In: Fairbanks DNF, Fujita S, eds. Snoring and obstructive apnea: an overview with historical perspectives. New York: Raven Press, 1987:1-18.

13 Lapresle J, Annabi A. Olivopontocerebellar atrophy with velopharyngolaryngeal paralysis: A contribution to the somatotopy of the nucleus ambiguus. F Neuropathol Exp
Neurol 1979;38:401-6.

14 Guindi GM, Bannister R, Gibson WPR, Payne JK. Laryngeal electromyography in multiple system atrophy
with autonomic failure. $\mathcal{f}$ Neurol Neurosurg Psychiatry with autonomic

15 Isozaki E. Clinicopathological, electromyographical, and phoniatric studies on bilateral vocal cord paralysis in multiple system atrophy. Kitakanto Med $\mathcal{f} 1991 ; 41$ : 389-409.

16 Kuna ST, Insalaco G, Woodson GE. Thyroarytenoid muscle activity during wakefulness and sleep in normal adults. f Appl Physiol 1988;65:1332-9.

17 Kuna ST, Smickly JM. Insalaco G. Posterior crycoarytenoid muscle activity during wakefulness and sleep in normal adults. $₹$ Appl Physiol 1990;68:1746-54.

18 Orem J, Lydic R. Upper airway function during sleep and wakefulness: experimental studies on normal and anesthetized cats. Sleep 1978;1:49-68.

19 Isozaki E, Shimizu T, Takamoto K. Vocal cord abductor paralysis (VCAP) in Parkinson's disease: difference from VCAP in multiple system atrophy. $\mathcal{F}$ Neurol Sci 1995;130: VCAP in
$197-202$.

20 Osanai R, Hayashida T, Isozaki E, Murofushi T, Tanabe $H$. Bilateral vocal cord abductor impairment in a patient with spinocerebellar degeneration with a detailed report on relatively acute laryngeal symptoms. Fibi Rinsho 1990; 83:1679-86

21 Hawthorne MR, Nunez DA. Bilateral vocal cord palsy: the alternative to tracheostomy. $\mathcal{F}$ Ololaryngol 1992;21:364-5.

22 Eckel HE, Thumfart $M$, Wassermann $K$, Vossing $M$ Thumfart WF. Cordectomy versus arytenoidectomy in the management of bilateral vocal cord paralysis. Ann Otol Rhinol Laryngol 1994;103:852-7.

23 Kenyon GS, Apps MCP, Traub M. Stridor and obstructive sleep apnea in Shy-Drager syndrome treated by laryngofissure and cord lateralization. Laryngoscope 1984;94: gofissure $1106-8$. 